\title{
Validation of a new experimental model of extrusive luxation on maxillary molars of rats: a histological study
}

\author{
Luciana Artioli Costa ${ }^{1}$. Luana Martins Cantanhede ${ }^{2} \cdot$ Erika Martins Pereira $^{2} \cdot$ Marcelo Macedo Crivelini $^{1}$. \\ Osmar Aparecido Cuoghi ${ }^{1}$ - Alex Luiz Pozzobon Pereira ${ }^{2}$ • Marcos Rogério de Mendonça ${ }^{1,3}$
}

Received: 28 November 2016 / Accepted: 21 November 2017 / Published online: 6 December 2017

(C) Springer-Verlag GmbH Germany, part of Springer Nature 2017

\begin{abstract}
Background/aim The aim of this study was to test and validate a new model of extrusive luxation trauma on maxillary first molars of rats.

Material and methods Forty adult male rats (Rattus norvegicus albinus, Wistar; weight $=230-250 \mathrm{~g}$ ), 45 days old, were divided into eight groups $(n=5)$ : control groups, in which animals were not subjected to any procedure and waited 1 day (GC1D) or 3 days (GC3D) for euthanasia, and experimental groups, in which animals were subjected to forces of $1100 \mathrm{cN}, 1300 \mathrm{cN}$, or $1500 \mathrm{cN}$ and waited 1 or 3 days for euthanasia (GT1100/1D, GT1100/3D, GT1300/1D, GT1300/3D, GT1500/1D, GT1500/3D). In animals of the experimental groups, trauma was produced by an extrusive force in maxillary first right molars. Fourmicrometer serial cuts stained with hematoxylin and eosin (HE) were made. Descriptive microscopic analysis of first upper right molar and semi-quantitative analysis (scores 1 to 4) of intensity of acute and chronic inflammation and vascular changes in the periodontal ligament and active and inactive external root resorption were conducted. The distribution of scores in the groups was compared using the Freeman-Halton extension of Fisher's exact test. The significance level was 5\%.

Results It was observed that vascular disorders (bleeding) on the periodontal ligament became more evident with increasing extrusive force.

Conclusions This new method was capable of generating histological changes, proving its secure application in this research area. The $1500 \mathrm{cN}$ force produced more damage on the periodontal ligament.

Clinical relevance The validation of a new experimental method can produce more reliable evidence in further research.
\end{abstract}

Keywords Tooth injuries $\cdot$ Dental trauma $\cdot$ Models $\cdot$ Animal $\cdot$ Validation studies

\section{Introduction}

The treatment protocols related to traumatic dental injuries are still considered contradictory in many cases [1]. The low incidence of some types of dental traumatism, such as the extrusive luxation, and the need for multidisciplinary treatment,

Marcos Rogério de Mendonça

marcosrm@ foa.unesp.br

1 Dental School of Araçatuba, São Paulo State University (UNESP), José Bonifácio Street, 1193, Araçatuba, SP 1601-050, Brazil

2 Federal University of Maranhão, Portugueses Avenue, 1966 - Vila Bacanga, São Luís, MA 65085-580, Brazil

3 Department of Orthodontics, Dental School of Araçatuba, São Paulo State University (UNESP), José Bonifácio Street, 1193, Araçatuba, SP 1601-050, Brazil makes it difficult to conduct studies that produce reliable evidence [1-3]. In addition, the emergency characteristics related to traumatic dental injuries preclude the conduct of clinical trials in humans for ethical reasons [1].

Extrusive luxation is defined as the partial displacement of the tooth out of the alveolus [4] and represents a severe lesion to the periodontal ligament and pulp [5]. The repair process related to this kind of dental traumatism is scarce in the literature. Animal models are one of the methods used in the pursuit of understanding the sequelae and treatment measures of dental trauma [6], as these models occupy the base of the pyramid of scientific evidence [7]. Studies related to traumatic dental injuries conducted experimentally in rats have helped the understanding of the histogenesis of traumatic changes in the development of tooth germ [8], the biological events involved in dental re-implantation [9], as well as events occurring after the luxation of immature teeth [10]. 
A challenge for researches is the use of an experimental method which produces effects related to the experimental procedure made, reducing the bias inherent to scientific method. In this aspect, the validation of new methods is essential as a mean of strengthen the results. In the dental trauma studies, it is not different, and concern has been expressed by researchers to validate their working methods $[6,11-13]$.

Thus, the objective of this research was to test, evaluate, and validate a new method of dental trauma simulation, extrusive luxation type, on maxillary first molars of rats.

\section{Material and methods}

This research was performed in accordance with the criteria established in the ARRIVE guidelines [14]. The research protocol was approved by the Ethics Committee on Animal Use of the Dental School, "Julio de Mesquita Filho" São Paulo State University, Araçatuba, São Paulo, Brazil (protocol no. 2014-00815). All experimental procedures were made between February and June of 2015.

Forty young adult male rats (Rattus norvegicus albinus, Wistar), aged 45 days and weighing 230-250 $\mathrm{g}$ at the beginning of the procedures, obtained from São Paulo State University's bioterium, were used. The animals were kept in plastic cages under controlled climate conditions with a light cycle of 12/12 $\mathrm{h}$ and constant temperature and were fed with solid feed (Ração Ativada Produtor ${ }^{\circledR}$; Anderson \& Clayton S.A., Abbott Laboratories, São Paulo, SP, Brazil) and water ad libitum. The cages were sanitized every other day, and no postsurgical analgesic was administered to avoid interferences in the inflammatory process [15] related to the repair of the structures that are the object of this study.

All procedures were performed under general anesthesia. The animals received an intramuscular injection of xylazine hydrochloride (Dopaser; Caleir S.A., Barcelona, Spain; $0.03 \mathrm{ml}$ per $100 \mathrm{~g}$ body weight) and ketamine hydrochloride (VETASET; Fort Dodge Animal Health, Iowa, USA; $0.07 \mathrm{ml}$ per $100 \mathrm{~g}$ body weight). The animals were randomly divided into eight groups $(n=5)$ as described in Table 1. For that, the animals received a random number between 1 and 40. Then, a random sequence was generated on Excel 2010 for Windows program, and the animals were allocated for each group following that sequence.

\section{Conducting the extrusive luxation trauma}

Extrusive luxation trauma was induced experimentally in the right first maxillary molars of the animals. The rats were placed in an operating table in the supine position. Their legs were trapped to restrict movement, the heads were kept still, and their mouths remained open during the procedures [11].

To perform the extrusive luxation, the following protocol was used (Fig. 1):
Table 1 Group division

\begin{tabular}{ll}
\hline Groups & Procedures \\
\hline Group control, 1 day (GC1D) & No procedure \\
& Euthanasia after 1 day \\
Group control, 3 days (GC3D) & No procedure \\
& Euthanasia after 3 days \\
Group trauma, 1100cN, 1 day & Trauma of EL with \\
(GT1100/1D) & $1100 \mathrm{cN}$ \\
& Euthanasia after 1 day \\
Group trauma, 1300cN, 1 day & Trauma of EL with \\
(GT1300/1D) & $1300 \mathrm{cN}$ \\
Group trauma, 1500cN, 1 day & Euthanasia after 1 day \\
(GT1500/1D) & Trauma of EL with \\
& $1500 \mathrm{cN}$ \\
Group trauma, 1100cN, 3 days & Euthanasia after 1 day \\
(GT1100/3D) & Trauma of EL with \\
& $1100 \mathrm{cN}$ \\
Group trauma, 1300cN, 3 days & Euthanasia after 3 days \\
(GT1300/3D) & Trauma of EL with \\
Group trauma, 1500cN, 3 days & $1300 \mathrm{cN}$ \\
(GT1500/3D) & Euthanasia after 3 days \\
& Trauma of EL with \\
& $1500 \mathrm{cN}$ \\
\hline
\end{tabular}

1. A 0.010-in. ligature wire (Morelli ${ }^{\circledR}$; Sorocaba, São Paulo, Brazil) was inserted, with the aid of a clinical Perry model clamp (Golgran; São Caetano do Sul, São Paulo, Brazil), from the buccal to lingual direction between the first and second maxillary right molars (Fig. 1a).

2. The two ends of the wire were placed on the mesial side of the first maxillary molar and twisted in the form of a pig tail, with the aid of a Mathieu 17.0-cm needle holder (Quinelato; Rio Claro, São Paulo, Brazil), until the wire fit and remained close to the animal's tooth (Fig. 1b).

3. A dental mirror handle (Golgran; São Caetano do Sul, São Paulo, Brazil) was positioned between the two remaining ends of the wire, and a new twist was performed (Fig. 1c), to create a ring in which the tensiometer's active end was adapted (model 75.02.006; Morelli, Sorocaba, São Paulo, Brazil) and placed (Fig. 1d).

4. The tensiometer was positioned on an adjustable support device as described by Pereira et al. [11], but with a traction angle of $60^{\circ}$ to the vertical plane of the biarticulated arm (Fig. 1e).

5. Forces of $1100 \mathrm{cN}, 1300 \mathrm{cN}$, or $1500 \mathrm{cN}$ were applied for $5 \mathrm{~s}$ (Fig. 1f), and the device was removed.

After the end of experimental period for each group, the animals were euthanized by an overdose of anesthetic (sodium pentobarbital, $150 \mathrm{mg} / \mathrm{kg}$ ) and then decapitated. The maxilla was fixed in buffered $10 \%$ formalin for $48 \mathrm{~h}$. 


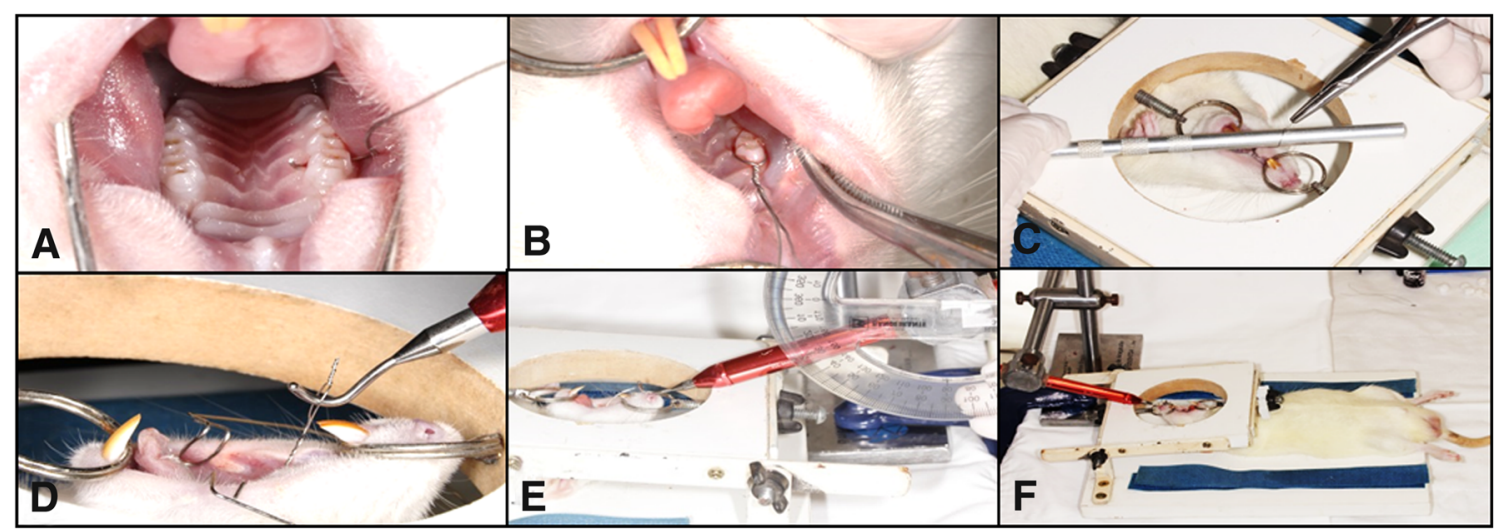

Fig. 1 a-f Method of trauma application

The right hemi-maxilla of each animal was decalcified in $10 \%$ Plank-Rychlo solution for 8 days, embedded in paraffin, and cut into $4-\mu \mathrm{m}$ serial cuts (sections) in the longitudinal direction of the root. A histological slide with three sections of each specimen was created and stained with hematoxylin and eosin (HE).

\section{Inclusion criteria for the selection of histological section}

The selected sections for analysis were chosen by the following inclusion criteria: (a) microscopic visualization of the entire longitudinal extent of the buccal mesial root and buccal distal root of the first upper right molar, (b) the presence of open apical foramen, and (c) the presence of interradicular septum (Fig. 2a, b). Of the three sections presented in each slide, the one that mostly suited the inclusion criteria was evaluated. Thus, one section per slide, per specimen was evaluated.

\section{Assessment of histological sections}

For descriptive and semi-quantitative histological analysis, a light microscope (Leica Microsystems, Wetzlar GmbH, Germany) was used. To obtain the photomicrographs, with magnifications of $\times 200$ and $\times 400$, a digital camera $(J V C$; Victor Company of Japan, Ltd., Japan) attached to the microscope was used. The images were captured using the Leica QWin Standard v2.4 software (Leica Microsystems Imaging Solutions, Ltd., Cambridge, UK) for further analysis.

The specific areas of the study for descriptive analysis were the following: (1) the periodontium of the mesial and distal sides of buccal mesial and buccal distal roots in the cervical, middle, and apical thirds; (2) the periodontium of the furcation region; (3) the mesial bone crest; (4) the interradicular septum; and (5) the interdental septum between the first and second upper right molars (Fig. 3). The histopathological events that were investigated were external root resorption, areas of hyalinization, inflammatory infiltrate, the presence of giant multinucleate cells, and the presence of bleeding. Each event was evaluated as follows: -, absence; + , occasional presence; ++ , moderate presence; and +++ , intense presence.

\section{Semi-quantitative analysis}

For the quantification of histological events, scores 1 to 4 were assigned for the different events listed below. Specific areas of this analysis were (1) the distal root, mesial side, and cervical and middle thirds; (2) the mesial root, distal side, and cervical and middle thirds; (3) mesial, middle, and distal furcation; and (4) mesial side of the mesial buccal root (adjacent region mesial bone crest).
Fig. 2 Representation of a typical histological cut. a Histological cut of the first upper right molar of a rat $(\times 4$ magnification). $\mathbf{b}$ Representation of the upper right first molar of a rat

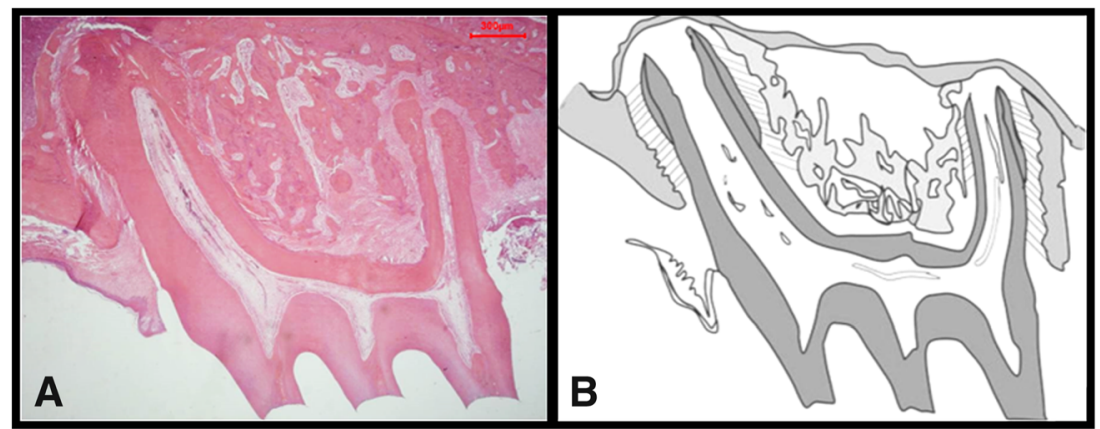


The events investigated and their respective scores were as follows:

1. Intensity of acute inflammatory process (presence of polymorphonuclear cells) in the periodontal ligament [16]

(a) Absence or occasional presence of inflammatory cells

(b) Small number of inflammatory cells, up to 10 cells per field with a magnification of $\times 400$

(c) Moderate number of inflammatory cells, from 11 to 50 cells per field with a magnification of $\times 400$

(d) Large number of inflammatory cells, above 50 inflammatory cells per field with a $\times 400$ magnification

2. Intensity of chronic inflammation (multinucleated giant cells) in the periodontal ligament [16]

(a) Absence or occasional presence of inflammatory cells

(b) Small number of inflammatory cells, up to 10 cells per field with a magnification of $\times 400$

(c) Moderate number of inflammatory cells, from 11 to 50 cells per field with a magnification of $\times 400$

(d) Large number of inflammatory cells, above 50 inflammatory cells per field with $\mathrm{a} \times 400$ magnification

3. Vascular changes in the periodontal ligament (Fig. 4)

(a) Absence or occasional presence of blood vessels

(b) Presence of hyperemic blood vessels

(c) Presence of light bleeding (some loose red blood cells in the ligament)

(d) Bleeding of the periodontal ligament (many free red blood cells in the periodontal ligament)

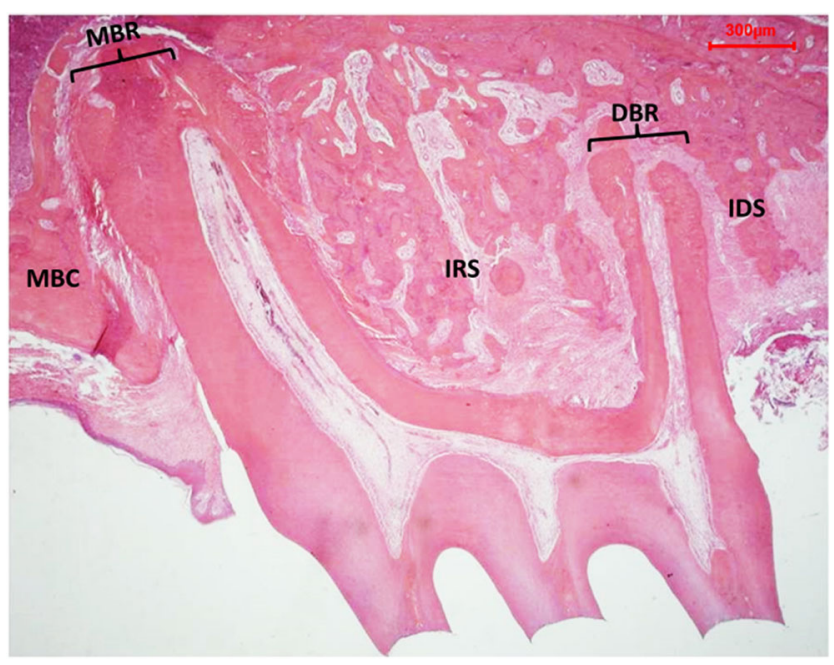

Fig. 3 Areas assessed. MBR mesial buccal root, DBR distal buccal root, MBC mesial bone crest, IRS interradicular septum, IDS interdental septum
4. Active and inactive external root resorption [16]

(a) Absence of resorption area

(b) Presence of inactive resorption area (absence of clastic cells)

(c) Presence of small areas of active resorption

(d) Presence of extensive areas of active resorption

The variables were summarized using relative frequency measurements. For statistical analysis, the SPSS software features (version 17.0) were used. The distribution of scores between the experimental groups and control group and that between the experimental groups at different times were compared using the Freeman-Halton extension of Fisher's exact test. The significance level was $5 \%$.

\section{Results}

\section{Descriptive analysis}

\section{Control groups}

Histological characteristics of control groups GC1D and GC3D were not different. The periodontal ligament had normal characteristics and was rich in fibroblasts. The collagen fibers were arranged obliquely in relation to the root surface in the mesial and distal sides of both roots, horizontally in the furcation region, and disorganized in the root apex region. There were no areas of hyalinization or presence of inflammatory infiltrate and multinucleated giant cells in any of the animals. The root surfaces were completely intact. The interradicular septum had a normal appearance. The bone crest appeared normal. The dental cementum is continuous up to the apex.

\section{GT1100/1D}

The periodontal ligament had light bleeding, particularly in the furcation region in all animals, with no inflammatory infiltrates. Areas of hyalinization or external root resorption were not found in any of the specimens. Rare multinucleated giant cells were observed on the surface of the mesial bone crest, interradicular septum, and interdental septum. The dental cementum had a normal appearance.

\section{GT1300/1D}

The periodontal ligament had moderate bleeding, particularly in the furcation area of all animals. There were no inflammatory infiltrates. Areas of hyalinization or external root resorption were not found in any of the specimens. Rare 


\begin{tabular}{|c|c|c|c|c|}
\hline Area & Score 1 & Score 2 & Score 3 & Score 4 \\
\hline & $\begin{array}{l}\text { (RS } \\
\text { 1RS }\end{array}$ & 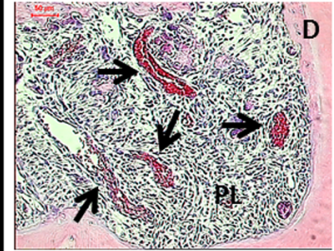 & 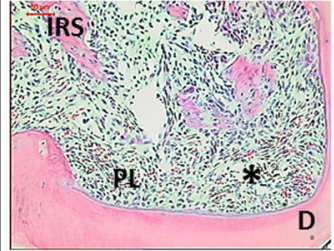 & 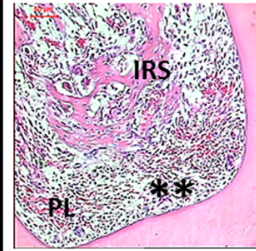 \\
\hline
\end{tabular}

Notes: IRS - inter-radicular septum; PL - periodontal ligament; D - dentin; Arrows indicate hyperemic blood vassels; Asterisk indicate loose red blood cells.

Fig. 4 Example of semi-quantitative scoring of vascular changes. Score 1 , absence or occasional presence of blood vessels; score 2, presence of hyperemic blood vessels; score 3, presence of light bleeding (some loose red blood cells in the ligament); score 4 , bleeding of the periodontal

multinucleated giant cells were observed on the surface of the mesial bone crest, interradicular septum, and interdental septum.

\section{GT1500/1D}

The periodontal ligament had severe areas of bleeding, particularly in the furcation region in all animals. There were no acute inflammatory infiltrates in the periodontal ligament. Areas of hyalinization were not found in any of the specimens. Two animals showed external root resorption, but only in the cervical third of the mesial side of the mesial buccal root. Rare multinucleated giant cells were observed on the surface of the mesial bone crest and interradicular septum.

\section{GT1100/3D}

The periodontal ligament had normal characteristics, except for rare free red blood cells in the PL. There were no acute inflammatory infiltrates in the periodontal ligament. Areas of hyalinization or external root resorption were not found in any of the specimens. Rare multinucleated giant cells were ligament (many free red blood cells in the periodontal ligament). IRS interradicular septum, PL periodontal ligament, D dentin. Arrows indicate hyperemic blood vessels. Asterisks indicate loose red blood cells. Area of observation - cervical third, mesial side of buccal distal root

observed on the surface of the mesial bone crest, interradicular septum, and interdental septum.

\section{GT1300/3D}

The periodontal ligament had a few congested blood vessels, particularly in the distal furcation region. There were no acute inflammatory infiltrates in the periodontal ligament. Areas of hyalinization or external root resorption were not found in any of the specimens. Rare multinucleated giant cells were observed on the surface of mesial bone crest, interradicular septum, and interdental septum.

\section{GT1500/3D}

The periodontal ligament had many congested blood vessels, particularly in the furcation region. There were no acute inflammatory infiltrates in the periodontal ligament. Areas of hyalinization or external root resorption were not found in any of the specimens. Rare multinucleated giant cells were observed on the surface of the mesial bone crest, interradicular septum, and interdental septum.

The results are shown in Table 2 and Figs. 4 and 5.
Table 2 Summary of the descriptive analysis

\begin{tabular}{llllll}
\hline Groups & Bleeding & $\begin{array}{l}\text { Congested } \\
\text { vessels }\end{array}$ & $\begin{array}{l}\text { Chronic } \\
\text { inflammatory } \\
\text { infiltrate }\end{array}$ & $\begin{array}{l}\text { Acute } \\
\text { inflammatory } \\
\text { infiltrate }\end{array}$ & $\begin{array}{l}\text { Areas of active } \\
\text { resorption in IS }\end{array}$ \\
\hline GC1D/3D & - & - & + & - & - \\
GT1100/1D & + & - & + & - & - \\
GT1300/1D & ++ & - & + & - & - \\
GT1500/1D & +++ & - & + & - & - \\
GT1100/3D & + & - & + & - & - \\
GT1300/3D & + & + & + & - & - \\
GT1500/3D & + & +++ & + & - & \\
\hline
\end{tabular}

-, absence; + occasional presence; ++ moderate presence; +++ intense presence

IS interradicular septum 


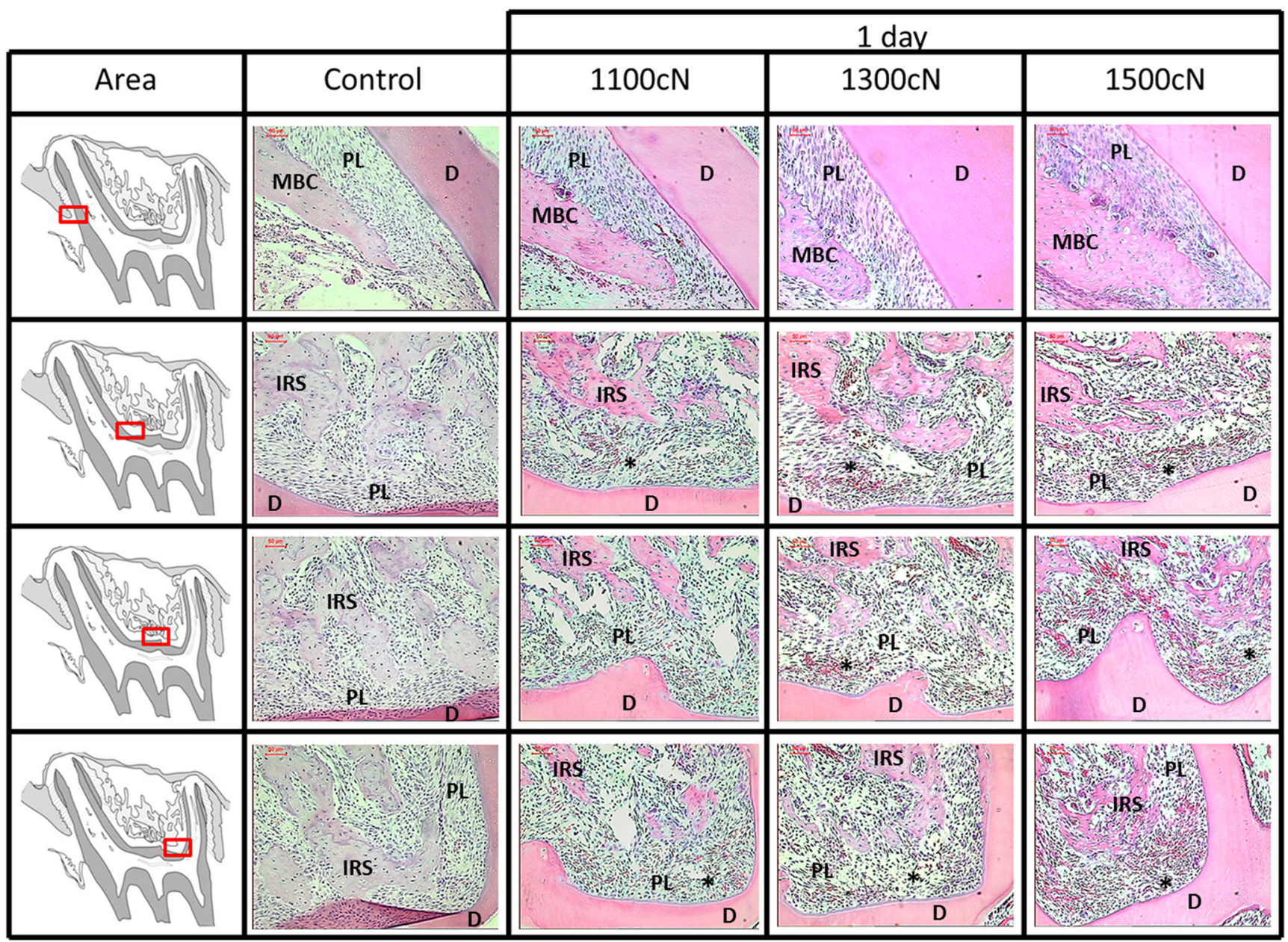

Notes: MBC - mesial bone crest; IRS - inter-radicular septum, PL - periodontal ligament; D - dentin; Arrows indicate hyperemic

blood vassels; Asterisk indicate loose red blood cells

Fig. 5 Summary of findings for day 1. It can be observed that the periodontal ligament had more severe bleeding areas with the increase on magnitude of extrusive force applied. MBC mesial bone crest, IRS

\section{Semi-quantitative analysis}

On the evaluation of acute and chronic inflammatory process in the periodontal ligament and reabsorption of the interradicular septum, score 1 was found on $100 \%$ of samples at 1 and 3 days (Fig. 6).

Table 3 describes the distribution of scores for the vascular changes in the evaluated anatomic regions in absolute frequency and relative frequency. It is shown that vascular alterations in $1500 \mathrm{cN}$ force groups, especially on furcation area, reach scores 3 and 4 , the most intense ones. These results are confirmed by the statistical analysis presented in Table 4, suggesting that the vascular alterations occur more intensely on the first day in $1300 \mathrm{cN}$ and $1500 \mathrm{cN}$ groups and decrease on the third day, except on middle furcation $(p=0.04)$ and distal furcation $(p=$ 0.04 ) in the $1500 \mathrm{cN}$ group. interradicular septum, PL periodontal ligament, D dentin. Asterisks indicate loose red blood cells. The red rectangles represent the area of observation

\section{Discussion}

An experimental method for studies of dental trauma in rat molars was presented and evaluated. This method was effective for this kind of study because it allowed extrusive luxation simulation generating changes that can be 


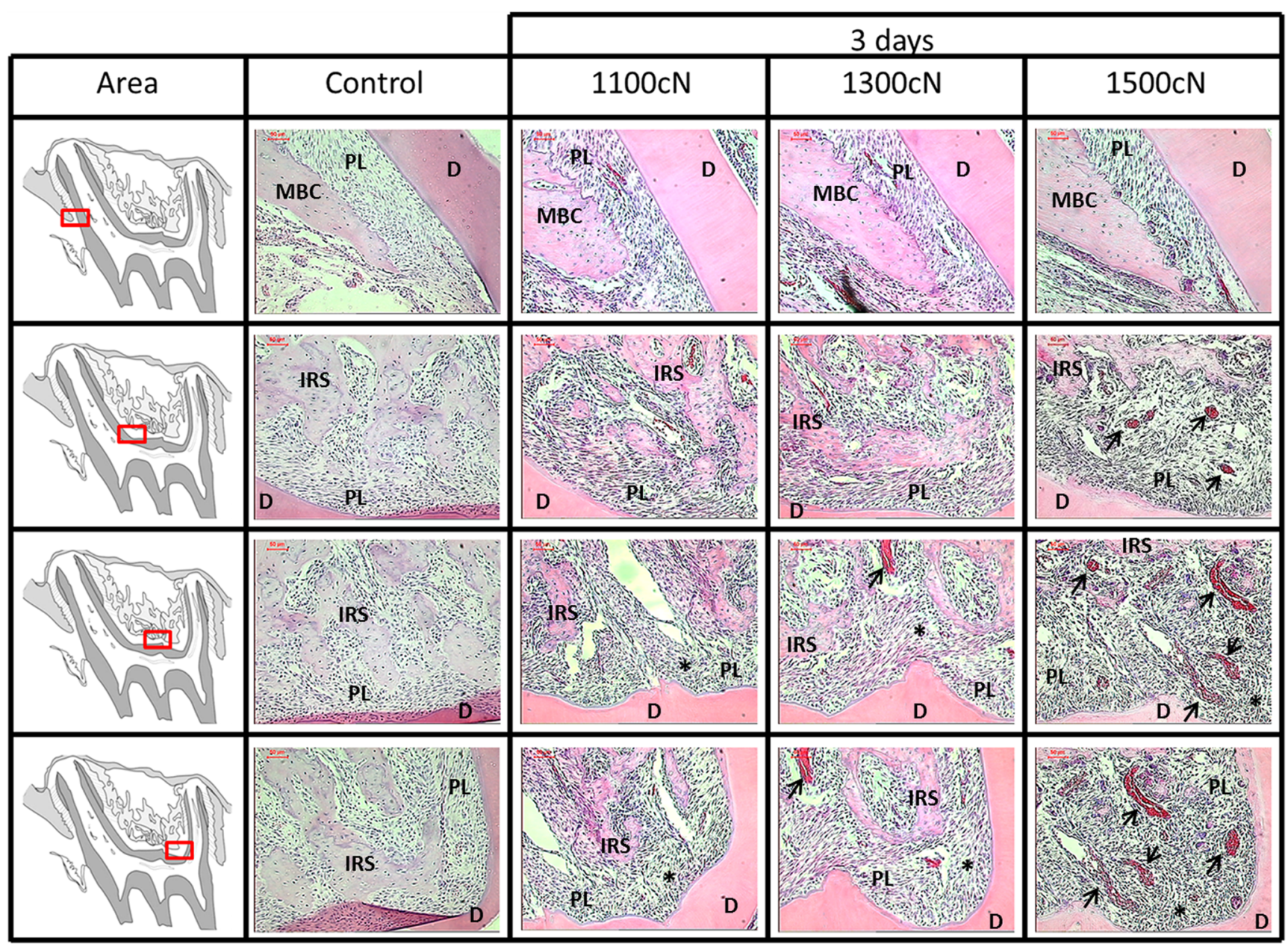

Notes: MBC - mesial bone crest; IRS - inter-radicular septum, PL - periodontal ligament; D - dentin; Arrows indicate hyperemic

blood vassels; Asterisk indicate loose red blood cells

Fig. 6 Summary of findings for day 3. It can be observed that the periodontal ligament had more hyperemic blood vessels on the group where a higher magnitude of extrusive force was applied. MBC mesial

observed microscopically and that were directly related to the procedure made.

In humans, extrusive luxation represents a severe lesion to the periodontal ligament and pulp [5]. A human molar is approximately 50 times larger than a rat molar [17]. Thus, the forces used in this study $(1.100 \mathrm{cN}, 1.300 \mathrm{cN}$, and $1.500 \mathrm{cN}$ ) are comparable to $55.000 \mathrm{cN}, 65.000 \mathrm{cN}$, and $75.000 \mathrm{cN}$ on a human molar, which represents the forces of approximately 550,650 , and $750 \mathrm{~kg}$, respectively. Those forces were capable to generate such stress that results on bleeding of the periodontal ligament that are compatible to extrusive luxation traumatism [4].

The most striking result in response to the induced dental trauma was vascular changes, specifically bleeding in the periodontal ligament when $1500 \mathrm{cN}$ force was applied on day 1 (GT1500/1D). The standardization of angulation and the forces used generated homogeneous microscopic changes bone crest, IRS interradicular septum, PL periodontal ligament, D dentin. Arrows indicate hyperemic blood vessels. Asterisks indicate loose red blood cells. The red rectangles represent the area of observation and were compatible with the induced dental traumatism throughout the studied sample.

The tensiometer used to perform the dental trauma allowed for the standardization of force in its magnitude. The biarticulated arm, the same used by Pereira et al. [11], allowed for the standardization of the applied force direction (angle). The positive and differential features of this method were generated in uniformity in the biological responses that was found in every sample.

In the study of Birkedal-Hansen [18] that used surgical levers to traumatize rats' molars resulted in variability of inflammatory responses, possibly due to the lack of standardization of the magnitude and applied angle force to the rats' tooth.

In 1990, Miyashin et al. [6] developed a method to standardize the variables of duration, magnitude, and direction of force in the upper molars of rats with incomplete root formation. However, this method did not determine the forces 
Table 3 Distribution of scores for the vascular changes in the evaluated anatomic regions

\begin{tabular}{|c|c|c|c|c|c|c|c|c|}
\hline \multirow[t]{2}{*}{ Areas } & \multicolumn{4}{|l|}{1 day } & \multicolumn{4}{|l|}{3 days } \\
\hline & Control & $1100 \mathrm{cN}$ & $1300 \mathrm{cN}$ & $1500 \mathrm{cN}$ & Control & $1100 \mathrm{cN}$ & $1300 \mathrm{cN}$ & $1500 \mathrm{cN}$ \\
\hline \multicolumn{9}{|l|}{ Mesial root, mesial side } \\
\hline Cervical third (score 1) & $5(100 \%)$ & $5(100 \%)$ & $4(100 \%)$ & $5(100 \%)$ & $5(100 \%)$ & $5(100 \%)$ & $5(100 \%)$ & $4(100 \%)$ \\
\hline Middle third (score 1) & $5(100 \%)$ & $4(100 \%)$ & $4(100 \%)$ & $4(100 \%)$ & $5(100 \%)$ & $5(100 \%)$ & $4(100 \%)$ & $4(100 \%)$ \\
\hline \multicolumn{9}{|l|}{ Mesial root, distal side } \\
\hline \multicolumn{9}{|l|}{ Cervical third } \\
\hline Score 1 & $5(100 \%)$ & $2(40 \%)$ & $2(50 \%)$ & $0(0)$ & $5(100 \%)$ & $5(100 \%)$ & $5(100 \%)$ & $4(100 \%)$ \\
\hline Score 3 & $0(0)$ & $3(60 \%)$ & $2(50 \%)$ & $3(60 \%)$ & $0(0)$ & $0(0)$ & $0(0)$ & $0(0)$ \\
\hline Score 4 & $0(0)$ & $0(0)$ & $0(0)$ & $2(40 \%)$ & $0(0)$ & $0(0)$ & $0(0)$ & $0(0)$ \\
\hline \multicolumn{9}{|l|}{ Middle third } \\
\hline Score 1 & $5(100 \%)$ & $3(60 \%)$ & $2(50 \%)$ & $5(100 \%)$ & $5(100 \%)$ & $5(100 \%)$ & $5(100 \%)$ & $4(100 \%)$ \\
\hline Score 3 & $0(0)$ & $2(40 \%)$ & $2(50 \%)$ & $0(0)$ & $0(0)$ & $0(0)$ & $0(0)$ & $0(0)$ \\
\hline \multicolumn{9}{|l|}{ Mesial furcation } \\
\hline Score 1 & $5(100 \%)$ & $4(80 \%)$ & $0(0)$ & $1(20 \%)$ & $5(100 \%)$ & $5(100 \%)$ & $5(100 \%)$ & $2(50 \%)$ \\
\hline Score 2 & $0(0)$ & $0(0)$ & $0(0)$ & $0(0)$ & $0(0)$ & $0(0)$ & $0(0)$ & $2(50 \%)$ \\
\hline Score 3 & $0(0)$ & $1(20 \%)$ & $4(100 \%)$ & $2(40 \%)$ & $0(0)$ & $0(0)$ & $0(0)$ & $0(0)$ \\
\hline Score 4 & $0(0)$ & $0(0)$ & $0(0)$ & $2(40 \%)$ & $0(0)$ & $0(0)$ & $0(0)$ & $0(0)$ \\
\hline \multicolumn{9}{|l|}{ Middle furcation } \\
\hline Score 1 & $5(100 \%)$ & $0(0)$ & $0(0)$ & $0(0)$ & $5(100 \%)$ & $5(100 \%)$ & $5(100 \%)$ & $1(25 \%)$ \\
\hline Score 2 & $0(0)$ & $0(0)$ & $0(0)$ & $0(0)$ & $0(0)$ & $0(0)$ & $0(0)$ & $3(75 \%)$ \\
\hline Score 3 & $0(0)$ & $4(80 \%)$ & $4(100 \%)$ & $2(40 \%)$ & $0(0)$ & $0(0)$ & $0(0)$ & $0(0)$ \\
\hline Score 4 & $0(0)$ & $1(20 \%)$ & $0(0)$ & $3(60 \%)$ & $0(0)$ & $0(0)$ & $0(0)$ & $0(0)$ \\
\hline \multicolumn{9}{|l|}{ Distal furcation } \\
\hline Score 1 & $5(100 \%)$ & $0(0)$ & $0(0)$ & $0(0)$ & $5(100 \%)$ & $5(100 \%)$ & $5(100 \%)$ & $1(25 \%)$ \\
\hline Score 2 & $0(0)$ & $0(0)$ & $0(0)$ & $0(0)$ & $0(0)$ & $0(0)$ & $0(0)$ & $0(0)$ \\
\hline Score 3 & $0(0)$ & $4(80 \%)$ & $4(100 \%)$ & $1(20 \%)$ & $0(0)$ & $0(0)$ & $0(0)$ & \\
\hline Score 4 & $0(0)$ & $1(20 \%)$ & $0(0)$ & $4(80 \%)$ & $0(0)$ & $0(0)$ & $0(0)$ & $0(0)$ \\
\hline \multicolumn{9}{|l|}{ Distal root, mesial side } \\
\hline \multicolumn{9}{|l|}{ Cervical third } \\
\hline Score 1 & $5(100 \%)$ & $5(100 \%)$ & $1(25 \%)$ & $0(0)$ & $5(100 \%)$ & $5(100 \%)$ & $5(100 \%)$ & $3(75 \%)$ \\
\hline Score 2 & $0(0)$ & $0(0)$ & $0(0)$ & $0(0)$ & $0(0)$ & $0(0)$ & $0(0)$ & $1(25 \%)$ \\
\hline Score 3 & $0(0)$ & $0(0)$ & $3(75 \%)$ & $3(60 \%)$ & $0(0)$ & $0(0)$ & $0(0)$ & $0(0)$ \\
\hline Score 4 & $0(0)$ & $0(0)$ & $0(0)$ & $2(40 \%)$ & $0(0)$ & $0(0)$ & $0(0)$ & $0(0)$ \\
\hline \multicolumn{9}{|l|}{ Middle third } \\
\hline Score 1 & $5(100 \%)$ & $5(100 \%)$ & $4(100 \%)$ & $4(100 \%)$ & $5(100 \%)$ & $5(100 \%)$ & $4(100 \%)$ & $4(100 \%)$ \\
\hline
\end{tabular}

corresponding to different root formations [13]. In 1998, Shibue et al. [13] showed an extrusive force method based on the degree of root formation, but the proposed method is complex and used materials of difficult access.

In 2010, Pereira et al. [11] suggested a subluxation method with a standardization of the force used. This method, however, uses an intrusive force and does not standardize the angle of force application.

The reliability of an experimental method is related to its ability to allow reproducibility of all characteristics of the tested procedures with similar biological results. In this aspect, the method presented here is shown to be efficient and effective.

The extrusive luxation method proposed produced a tooth displacement in the occlusal mesial direction, featured a controlled tilting movement (rotation), and was capable of forming compression and stretching areas on the periodontal ligament that were very similar. This resulted in similar histological responses in every sample (Fig. 7).

The initial phase of the inflammatory process is a vascularexudative phenomenon which develops between days 1 and 3 in humans and culminates in its resolution or chronification 
Table 4 Statistical analysis of vascular changes in between experimental groups $(1100 \mathrm{cN}, 1300 \mathrm{cN}$, or $1500 \mathrm{cN})$ and control group and between experimental groups at different times

\begin{tabular}{|c|c|c|c|c|c|c|c|c|c|}
\hline \multirow[t]{2}{*}{ Areas } & \multicolumn{3}{|l|}{1 day } & \multicolumn{3}{|l|}{3 days } & \multicolumn{3}{|c|}{1 versus 3 days } \\
\hline & $1100 \mathrm{cN}$ & $1300 \mathrm{cN}$ & $1500 \mathrm{cN}$ & $1100 \mathrm{cN}$ & $1300 \mathrm{cN}$ & $1500 \mathrm{cN}$ & $1100 \mathrm{cN}$ & $1300 \mathrm{cN}$ & $1500 \mathrm{cN}$ \\
\hline \multicolumn{10}{|l|}{ Mesial root, mesial side } \\
\hline Cervical third (score 1) & 1.00 & 1.00 & 1.00 & 1.00 & 1.00 & 1.00 & 1.00 & 1.00 & 1.00 \\
\hline Middle third (score 1) & 1.00 & 1.00 & 1.00 & 1.00 & 1.00 & 1.00 & 1.00 & 1.00 & 1.00 \\
\hline \multicolumn{10}{|l|}{ Mesial root, distal side } \\
\hline Cervical third & 0.16 & 0.16 & $<0.01^{*}$ & 1.00 & 1.00 & 1.00 & 0.16 & 0.16 & $<0.01^{*}$ \\
\hline Middle third & 0.44 & 0.16 & 1.00 & 1.00 & 1.00 & 1.00 & 0.44 & 0.16 & 1.00 \\
\hline Mesial furcation & 0.49 & $<0.01 *$ & $0.04 *$ & 1.00 & 1.00 & 0.16 & 0.49 & $<0.01 *$ & 0.09 \\
\hline Middle furcation & $<0.01^{*}$ & $<0.01 *$ & $<0.01 *$ & 1.00 & 1.00 & $0.04 *$ & $<0.01 *$ & $<0.01 *$ & $<0.01^{*}$ \\
\hline Distal furcation & $<0.01 *$ & $<0.01 *$ & $<0.01 *$ & 1.00 & 1.00 & $0.04 *$ & $<0.01 *$ & $<0.01 *$ & $0.04 *$ \\
\hline \multicolumn{10}{|l|}{ Distal root, mesial side } \\
\hline Cervical third & 1.00 & $0.04 *$ & $<0.01 *$ & 1.00 & 1.00 & 0.44 & 1.00 & $0.04 *$ & $<0.01^{*}$ \\
\hline Middle third (score 1) & 1.00 & 1.00 & 1.00 & 1.00 & 1.00 & 1.00 & 1.00 & 1.00 & 1.00 \\
\hline
\end{tabular}

${ }^{*} p<0.05$, statistically significant differences (Freeman-Halton extension of Fisher's exact test)

[19]. To a great extent and as its main effect, the application of force causes bleeding.

The bleeding was the most striking biological response related to the model analyzed and is consistent with hemostasis of the repair process phase [4]. It was more exuberant in the periodontal ligament region adjacent to the distal furcation area, which is the region where the periodontal ligament has undergone great compression. This characteristic was even more exuberant as greater force was applied (Figs. 6 and 7).

Between the study limitations, it can be cited the impossibility of evaluation of some areas on histological cuts, decreasing the number of animals evaluated per group. Because the responses were very similar, it was decided not substitute or increase the number of animals. All efforts were made to attend the principles of animal use in scientific research.

The proposed method is simple and standardizes the angle and intensity of the applied force, producing similar biological responses across the sample without crown, root, or alveolar bone fractures. The validation of this trauma model allows new research to be conducted with the assurance that all the animals were exposed to the same type of trauma.

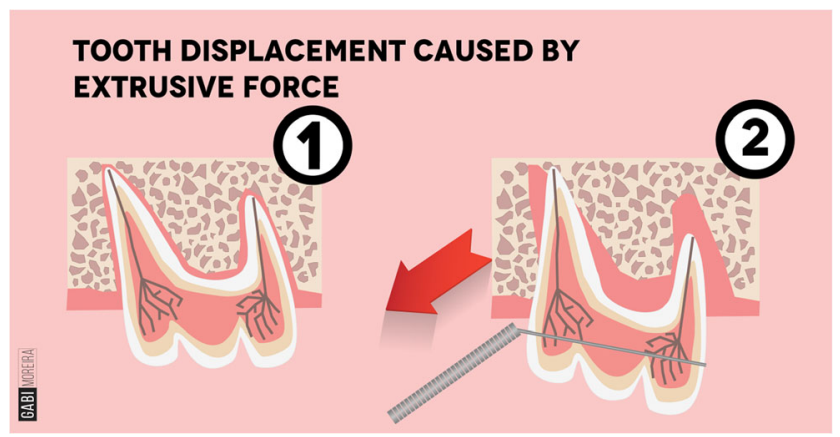

Fig. 7 Tooth displacement caused by extrusive force

\section{Conclusion}

The method tested was efficient for simulating the dental trauma of extrusive luxation, and the force magnitude of $1500 \mathrm{cN}$ was the most effective on producing biological damage.

Funding information We thank all the support provided by Vandilson Pinheiro Rodrigues and the funding of the Orthodontics Postgraduate Program, Araçatuba School of Dentistry, UNESP, Araçatuba, São Paulo, Brazil.

\section{Compliance with ethical standards}

Conflict of interest The authors declare that they have no competing interests.

Ethical approval All applicable international, national, and/or institutional guidelines for the care and use of animals were followed.

Informed consent For this type of study, formal consent is not required.

\section{References}

1. Andreasen JO, Lauridsen E, Andreasen FM (2010) Contradictions in the treatment of traumatic dental injuries and ways to proceed in dental trauma research. Dent Traumatol 26(1):16-22. https://doi. org/10.1111/j.1600-9657.2009.00818.x

2. Al-Badri S, Kinirons M, BOI C, Welbury RR (2002) Factors affecting resorption in traumatically intruded permanent incisors in children. Dent Traumatol 18(2):73-76. https://doi.org/10.1034/j.16009657.2002.180205.x

3. Belmonte FM, Macedo CR, Day PF, Saconato H, Fernandes Moça Trevisani V (2013) Interventions for treating traumatized permanent front teeth: luxated (dislodged) teeth. Cochrane Database of Syst Rev 30(4):CD006203. https://doi.org/10.1002/14651858. CD006203.pub2 
4. Andreasen JO, Andreasen FM, Andersson L (2007) Textbook and color atlas of traumatic injuries to the teeth, 4th edn. England, Oxford

5. Hermann NV, Lauridsen E, Ahrensburg SS, Gerds TA, Andreasen JO (2012) Periodontal healing complications following extrusive and lateral luxation in the permanent dentition: a longitudinal cohort study. Dent Traumatol 28(5):394-402. https://doi.org/10.1111/edt. 12000

6. Miyashin M, Kato J, Takagi Y (1990) Experimental luxation injuries in immature rat teeth. Endod Dent Traumatol 6(3):121-128. https://doi.org/10.1111/j.1600-9657.1990.tb00406.x

7. Skelly AC, Jens C (2011) Evidence-based medicine (EBM): origins and modern application to spine care. Evid Based Spine Care J 2(01):11-16. https://doi.org/10.1055/s-0030-1267081

8. Taniguchi K, Okamura K, Funakoshi T, Motokawa W (1999) The effect of mechanical trauma on the tooth germs of rat molars at various developmental stages: a histopathological study. Endod Dent Traumatol 15(1):17-25. https://doi.org/10.1111/j.1600-9657. 1999.tb00743.x

9. Shinoara J, Shibata T, Shimada A, Komatsu K (2004) The biomechanical properties of the healing periodontium of replanted rat mandibular incisors. Dent Traumatol 20(4):212-221. https://doi. org/10.1111/j.1600-9657.2004.00244.x

10. Miyashin M, Kato J, Takagi Y (1991) Tissue reactions after experimental luxation injuries in immature rat teeth. Endod Dent Traumatol 7(1):26-35. https://doi.org/10.1111/j.1600-9657.1991. tb00179.x

11. Pereira ALP, Mendonça MR, Sonoda CK, Cuoghi OA, Poi WR (2010) Histological evaluation of experimentally induced subluxation in rat molars and its implications on the management of orthodontic treatment. Dent Traumatol 26(1):37-42. https://doi. org/10.1111/j.1600-9657.2009.00837.x

12. Tziafas D (1988) Pulpal reactions following experimental acute trauma of concussion type on immature dog teeth. Endod Dent Traumatol 4(1):27-31. https://doi.org/10.1111/j.1600-9657.1988. tb00289.x

13. Shibue T, Taniguchi K, Motokawa W (1998) Pulp and root development after partial extrusion in immature rat molars: a histopathological study. Endod Dent Traumatol 14(4):174-181

14. Kilkenny C, Browne WJ, Cuthill IC, Emerson M, Altman DG (2010) Improving bioscience research reporting: the ARRIVE guidelines for reporting animal research. PLoS Biol 8(6): e1000412. https://doi.org/10.1371/journal.pbio.1000412

15. Krishnan V, Davidovitch Z (2006) The effect of drugs on orthodontic tooth movement. Orthod Craniofacial Res 9(2006):163-171. https://doi.org/10.1111/j.1601-6343.2006.00372.x

16. Panzarini SR, Holland R, de Souza V, Poi WR, Sonoda CK, Pedrini D (2007) Mineral trioxide aggregate as a root canal filling material in reimplanted teeth. Microscopic analysis in monkeys. Dent Traumatol 23(5):265-272. https://doi.org/10.1111/j.1600-9657. 2006.00456.x

17. Ren Y, Maltha JC, Kuijpers-Jagtman AM (2004) The rat as a model for orthodontic tooth movement - a critical review and a proposed solution. Eur J Orthod Oct 26(5):483-490. https://doi.org/10.1093/ ejo/26.5.483

18. Birkedal-Hansen H (1973) External root resorption caused by luxation of rat molars. Scand J Dent Res 81(1):47-61

19. Freire MO, Dyke TEV (2013) Natural resolution of inflammation. Periodontol 2000 63:149-164. https://doi.org/10.1111/prd.12034 